\title{
The Impact of E-learning on L2 Learning: A Paradigm of Action Research
}

\author{
Nazia Koonj ${ }^{1} \quad$ Dr. Shumaila Aijaz Memon ${ }^{2} \quad$ Syed Waqar Ali Shah ${ }^{3}$ \\ ${ }^{1}$ MS Scholar in English Linguistics, ${ }^{2}$ Assistant Professor, ${ }^{3}$ Lecturer, English Language Development Centre \\ Mehran University of Engineering \& Technology, Jamshoro, Sindh
}

\begin{abstract}
With the developments in science \& technology, the education system across the world has undergone a number of changes in pedagogical frameworks. The effective learning is not thought to be limited to classrooms, but it extends beyond the class relating it with involvement in real world situations. The $21^{\text {st }}$ century education thus highly prepares learners to compete in the world of rapid change and progress. L2 learning is also one such dimension that has been revisited over the past few decades. The use of modern technology and e-sources is at the core of learning and teaching practices. This study aims to investigate the learners' perceptions about e-learning in context of a foreign language i.e. English in case of Pakistan. The study is qualitative in nature. It uses action research paradigm to address the problem. The semi-structured interviews were conducted from students $(\mathrm{n}=10)$ who participated in collaborative writing in an online classroom using docs.google.com. The interview data was analyzed qualitatively using content analysis. The study found that online collaborative writing is an effective strategy to develop L2 learners' writing skills. The students are highly motivated to participate in online learning where the participants help each other to develop any piece of writing under the guidance of teacher. The study recommends that L2 learners' writing can be improved through online collaborative strategy under the guidance of L2 instructor. The study suggests that the use of technology in L2 learning and teaching through e-sources can enhance L2 learning comparatively better than that of teaching in a traditional classroom.
\end{abstract}

Keywords: E-learning, Action Research, Collaborative Writing, Technology, online Resources

DOI: $10.7176 / \mathrm{JLLL} / 68-02$

Publication date:May $31^{\text {st }} 2020$

\section{INTRODUCTION}

\subsection{Introduction:}

It is widely accepted that advances in information technology and new developments in learning science provide opportunities to create well - designed, learner-centered, interactive, affordable, efficient, flexible e-learning environments (Khan, 2005). With the developments in science \& technology, the education system across the world has undergone a number of changes in pedagogical frameworks. The $21^{\text {st }}$ century education highly prepares learners to compete in the world of rapid change and progress. L2 learning is also one such dimension that has been revisited over the past few decades. The effective learning is not thought to be limited to classrooms, but it extends beyond the class relating it with involvement in real world situations. The use of modern technology and e-sources is at the core of learning and teaching practices.

This study aims to investigate the learners' perceptions about e-learning in context of a foreign language i.e. English in case of Pakistan. One E-Learning framework that can foster collaboration among E-Learning professionals is the Flexible E-Learning Framework (Khan, 2005). The framework provides an organizing structure to understand E-Learning perspectives within the following eight dimensions: pedagogy, technology, interface design, evaluation, management, resource support, ethics and institution (Khan, 2005)

E-learning in higher education classrooms is a team endeavor. It needs a big network of all the stake holders (instructors, instruction designers, technology support staff etc. E-Learning professionals need to understand all eight dimensions and be cognizant that specific roles and responsibilities are dependent upon the combination of select dimensions to a greater or lesser degree. For example, instructors may be most involved with the E-Learning dimensions of pedagogy, evaluation, technology, and ethics. In contrast, instructional technology specialists may more heavily participate in the technology, interface design, and resource support dimensions. Using this framework, it is easy to recognize that no one professional has exclusive coverage over all dimensions of ELearning. Quality E-Learning occurs when there is sufficient overlap of roles across dimensions, expert professionals filling those roles, and good communication among professionals enacting their roles.

\subsection{AIMS \& OBJECTIVES:}

The study aims to investigate L2 Learners' perceptions about e-learning at Mehran University of Engineering \& Technology, Jamshoro, Sindh.

Based on this aim, the following objectives have been set:

- To investigate L2 learners' (Undergrads Engineering Students) perceptions about use of e-sources in facilitating L2 learning. 
- To explore L2 learners' perceptions as to what extent e-sources help develop language especially writing skills.

\subsection{RESEARCH QUESTIONS:}

The research questions of the present study are as under:

- What are L2 learners' perceptions about use of e-sources in facilitating L2 learning?

- To what extent e-sources do help develop language especially writing skills at undergraduate level at a public sector engineering university, Sindh Pakistan?

\section{LITERATURE REVIEW:}

\subsection{Introduction:}

In today's challenging world of modernization and socialization it is very important for the learners' to be strong in the machines, soft wares and technology. We believe that ICT and Web-based learning solutions help learners in getting different possibilities that will make the learning process more challenging and interesting (Gardner, 1991).

(Gottlieb) says that a digital revolution reaching from citizen journalism to pedagogy is being brought up by the modernity of the medium and its parallel developments in all other domains of human life.

Cronin (2002) and Pym (2005) have stressed, it is not enough to have an opinion - an educated person must express it to shape the society we live in. Indeed, much of the knowledge and ideas in the modern 2.0/3.0 Web world are related to who has the information and who has it first. And who else should be encouraged to learn to use it to the best of their capacity and following all the ethical principles than students of foreign languages, who in many ways are and become the window to/ from the world of their own society and culture.

\subsection{Adoption of Interactive Multimedia and E-Learning:}

Rogers' modeled a useful framework for studying the adoption process. Many studies of diffusion found that the way targeted adopters perceive the attributes of an innovation is critical and that these perceptions account for 49$87 \%$ of the variance in whether or not they adopt. Five significant concepts in the perceived attributes of innovations are (Rogers,

1995):

- Relative advantage: represents the additional benefit offered by the innovation in comparison with the existing offer on the market. The degree of relative advantage is often expressed as economic profitability, social prestige, and other benefits.

- Compatibility: the degree to which an innovation is perceived as consistent with the existing values, past experiences and needs of potential adopters.

- Complexity: the degree to which an innovation is perceived as relatively difficult to understand and use. The more simplistic and less complex the innovations are, the easier it is for someone to adopt.

- Observability: the degree to which the results of an innovation are visible to the society at large, or in a social/professional group. If the observed effects are perceived to be small or non-existent, then the likelihood of adoption is reduced.

- Trialability: The capacity of potential clients to interact with the innovation. This may include trying out parts of a program or having the opportunity to watch others using a new program.

\subsection{The 3p Model: Learning Experiences, Process and Effectiveness Model}

The 3P model of learning been developed by (Moore, 1993). The 3P's stand for presage, process and product. The pre-existing student variables and contextual and situational issues are the main components of presage section. Student's perceptions regarding their learning environment are assessed under the process part. These perceptions influence students' preferences of learning strategies and how these approaches are implemented. The performance outcomes of the students in the product section (Moore, 1993)

The 3P model of student learning:

Presage Student variables, intellectual capability (IC) and abilities, prior knowledge, subject area, teaching methods, personality, culture, home background, time constraints, and course structure.

Process Student motivation and behavior, learning strategies.

Product Exam results, self-concept, grade point average, satisfaction

Current research uses a modified version of Biggs and Moore (1993) model to evaluate these relationships among internal dimension factors, external dimension factors and pedagogical of students on their perception about the process of interactive multimedia e-learning and furthermore on the effectiveness of interactive multimedia elearning environment that affect creative user' decision of the adoption. 
3. RESEARCH METHODOLOGY:

3.1 RESEARCH DESIGN:

Qualitative which refers to participants' insights about any social issue under investigation (Chauhan, 2012)

\subsection{DATA COLLECTION TOOLS:} Semi-Structured Interviews

The researchers constructed some questions based on the topic to be investigated and further responses were elicited during the interview.

\subsection{SAMPLING, PARTICIPANTS \& ANALYSIS: \\ Purposive \\ Participants: Teachers $(n=5)$, Students $(n=10)$ \\ Content Analysis was used to codify interview data (Creswell, 2008).}

\subsection{ACTION RESEARCH:}

The main purpose of action research is to focus on action and research simultaneously. The practitioners in case of classroom issues identify a certain problem and plan a strategy or any techniques to implement it in order to resolve the problem.

Gopang (2015) et al mentions that AR includes the systematic collection of data after implementing a certain strategy on any action to be changed, modified or reinforced, analysis of data, reflection on findings for more observation and action.

\section{FINDINGS:}

The data collected from L2 learners was recorded, and heard several times to transcribe manually. The data was then codified into themes. The responses of the participants have been noted in responses to constructed themes/categories. The participants were given codes for ethical reasons. The participants were coded with P1 to P10.

The findings of the study are into three phases: Pre-Actional Phases, Actional Phase \& Post-Actional Phase.

\subsection{PRE-ACTIONAL PHRASE:}

A focus group interviews used before the conduct of research to investigate the problems involving writing skills.

L2 Engineering Students highlighted various problems involving writing skills. The most dominant issues included grammar, punctuation, spelling and appropriate use of vocabulary.

The pre-action phase also helped to know that L2 learners do not get a proper feedback on their writing due to overcrowded classes.

\subsection{ACTIONAL PHASE:}

At this stage, we planned a lesson for focus group participants to teach them writing skills online using docs.google.com application which is helpful to connect different participants as learners under teacher's control.

The teacher created a class online on docs.google.com and invited a focus group participants $(\mathrm{n}=10)$ who took part in collaborative writing.

The teacher had them write a story where all students kept adding a sentence to develop a story. Wherever the students made a mistake in language, teacher could see online and comment on the spot to correct the mistakes by giving them possible prompts/options.

\subsection{POST_ACTIONAL PHASE:}

The participants after being taught online were interviewed about the usefulness of online collaborative writing.

Their responses were divided into codes and themes and analysed qualitatively by reflecting on their responses.

Content Analysis was used to codify interview data

\section{FINDINGS \& DISCUSSION:}

The study found that online collaborative writing is an effective strategy to develop L2 learners' writing skills. The students are highly motivated to participate in online learning where the participants help each other to develop any piece of writing under the guidance of teacher.

The sample responses of participants are as:

P1: Online collaborative writing is useful since it provides instant feedback to correct grammar and other language errors.

P3: The main thing about e-sources especially docs.google.com is that all learners collaborate to produce 
any text which is more engaging and creative to do.

\section{RECOMMENDATION \& SUGGESTION:}

The study recommends that L2 learners' writing can be improved through online collaborative strategy under the guidance of L2 instructor. The study suggests that the use of technology in L2 learning and teaching through esources can enhance L2 learning comparatively better than that of teaching in a traditional classroom.

Moreover, the size of the class matters most. If it is $15-20$, the class can be controlled effectively.

\section{REFERENCES:}

1. Dörnyei, Z. (2001a). Teaching and Researching Motivation. Pearson Education Limited. Malaysia, LSP.

2. Gardner, H. (1991). The unschooled mind. How children think and how schools should teach. New York: Basic Books.

3. Gee, J. P. (2009). Är videospel bra vid inlärning? / Are videogames good for knowledge acquisition?/ In: Kulturens Studia Generalia. Svenska kulturfonden. Oy Nord Print. 8-23.

4. Gottlieb, H. (2008). Digitala pedagogiska artefakter - nya verktyg för pedagoger och intendenter. /Digital artefacts - new tools for teachers and museum personnell/. In: Kulturens Studia Generalia. Svenska kulturfonden. Oy Nord Print. 25-38.

5. Gopang, I. B., Soomro, A.F., Bughio, F.A (2015). Increasing motivation at University level: A paradigm of Action Research. Journal of Language Teaching and Research. Vol.6, No.1, pp.140-146

6. Gardner. (1991). Gee; 2009; , 15.

7. Gottlieb. (n.d.). 2009.

8. Khan. (2005).

9. Moore, B. a. (1993). 